Pacific Journal of Mathematic 


\section{CORRECTON TO “EQUIVALENCE AND PERPENDICULARITY OF GAUSSIAN PROCESSES”}

\section{J. FELDMAN}

It has been kindly pointed out to me by D. Lowdenslager that, as it stands, the argument in [1] only works when $\boldsymbol{L}_{2}(\mu)$ and $\boldsymbol{L}_{2}(\nu)$ are separable. In particular, the theorem of von Neumann from [2], which is used there, only holds in separable Hilbert spaces. Our theorem nevertheless holds in the non-separable case; an argument will be supplied here enabling one to go from the separable to the general case. We retain notation and terminology of [1].

For any countable subset $\boldsymbol{C}$ of $\boldsymbol{L}$, let $\mathscr{S}$ be the $\sigma$-subalgebra of $\mathscr{S}$ generated by $\boldsymbol{C}, \boldsymbol{L} \boldsymbol{c}$ the linear subspace of $\boldsymbol{L}$ spanned by $\boldsymbol{C}$, and $\mu_{\boldsymbol{C}}$, $\nu_{c}$ the restrictions of $\mu, \nu$ to $\mathscr{S}_{c} . \bigcup_{c} \mathscr{S}_{C}$ is a $\sigma$-algebra contained in $\mathscr{S}$, and, since each $x \in \boldsymbol{L}$ is in some $\boldsymbol{L} \boldsymbol{c}$, each $x$ in $\boldsymbol{L}$ is measurable with respect to $\bigcup_{c} \mathscr{S}_{c}$. Therefore $\mathscr{S}=\bigcup_{c} \mathscr{S}_{c}$. Now, suppose, under the assumptions of the theorem of [1], that $\mu$ and $\nu$ are not equivalent. Then there is some set in $\mathscr{S}$ with $\mu$-measure 0 and $\nu$-measure $>0$ (or vice versa). This set is in some $\mathscr{S}_{c}$. So $\mu_{c}$ and $\nu_{c}$ are not equivalent. By the separable case of the theorem, they are mutually perpendicular, i.e., there is some set in $\mathscr{S}_{C}$ with $\mu$-measure 0 and $\nu$-measure 1 . Thus $\mu$ and $\nu$ are mutually perpendicular.

Next we show that $\mu \sim \nu$ implies that the correspondence $x^{\nu} \stackrel{T}{\longrightarrow} x^{\mu}$ between equivalence classes of functions has the property that $T$ extends to an equivalence operator between the linear subspaces $\overline{\boldsymbol{L}}_{\mu}$ and $\overline{\boldsymbol{L}}_{\nu}$ of $\boldsymbol{L}_{2}(\mu)$, $\boldsymbol{L}_{2}(\nu)$ generated by $\boldsymbol{L}$. Assume, then, that $\mu \sim \nu$. By using the separable case, we easily see that $T$ and $T^{-1}$ are bounded. An argument on p. 704 of [1] still works to show that the extension of $T$ to an operator from $\overline{\boldsymbol{L}}_{\mu}$ onto $\overline{\boldsymbol{L}}_{\nu}$ still has the property that, given $\xi$ in $\overline{\boldsymbol{L}}_{\mu}$, there is an $\mathscr{S}$-measurable $x$ such that $x^{\mu}=\xi$ and $x^{\nu}=T \xi$. Write $T^{*} T$ as $\int \lambda d \mathrm{~F}(\lambda)$. Let $E_{n}=$ $F\left(1+\frac{1}{n}\right)-F\left(1-\frac{1}{n}\right), n=2,3,4, \cdots$ Let $E=\bigcap_{n} E_{n}$. I now assert $(I-E) \overline{\boldsymbol{L}}_{\mu}$ is separable. For otherwise $\left(I-E_{n}\right) \overline{\boldsymbol{L}}_{\mu}$ would be inseparable for some $n$, and one could therefore find a countable orthonormal infinite set $\xi_{1}, \xi_{2}, \cdots$ of elements of $\overline{\boldsymbol{L}}_{\mu}$ for which $\left\|\left(T^{*} T-I\right) \xi_{i}\right\| \geqq \frac{1}{n}\left\|\xi_{i}\right\|$, all $i$.

Let $\boldsymbol{H}$ be the Hilbert space spanned by the $\xi_{i}$. Let $\tilde{\boldsymbol{L}}$ be the set of $\mu$-measurable functions $x$ on $S$ such that $x^{\mu} \in \boldsymbol{H}$. Let $\dot{\mathscr{S}}$ be the $\sigma$-algebra spanned by them. Let $\tilde{\mu}, \tilde{\nu}$ be the completions of $\mu$ and $\nu$, restricted to $\tilde{\mathscr{S}}$. Then the Hilbert spaces $\overline{\tilde{\boldsymbol{L}}}_{\tilde{\mu}}, \overline{\tilde{\boldsymbol{L}}}_{\tilde{\nu}}$ are isometric to $\boldsymbol{H}$ and $T(\boldsymbol{H})$, 
respectively, in a natural way. Therefore they are separable, and, since $\tilde{\mu} \sim \tilde{\nu}$, the operator $\tilde{T}$ induced by the correspondence $\tilde{x}^{\mu} \longrightarrow \tilde{x^{\nu}}$ is an equivalence operator. But $T$ is unitarily equivalent to $T \mid \boldsymbol{H}$, and $T \mid \boldsymbol{H}$ was constructed so as not to be an equivalence operator, giving a contradiction.

To show $T$ is an equivalence operator, it suffices to show this for $T \mid(I-E) \overline{\boldsymbol{L}}_{\mu}$. Since $(I-E) \overline{\boldsymbol{L}}_{\mu}$ is separable, we can reduce to the separable case exactly as in the last five sentences of the previous paragraph, with $(I-E) \overline{\boldsymbol{L}}_{\mu}$ playing the role played there by $\boldsymbol{H}$ to show that $T$ is an equivalence operator.

Finally, suppose that, for $x \in \boldsymbol{L}, x^{\mu}=0 \Longleftrightarrow x^{\nu}=0$, and that the oneto-one operator $T$ from $\boldsymbol{L}_{\mu}$ to $\boldsymbol{L}_{\nu}$ induced thereby extends to an equivalence operator from $\overline{\boldsymbol{L}}_{\mu}$ to $\overline{\boldsymbol{L}}_{\nu}$. It must be shown that $\mu \sim \nu$. If $\mu$ is not equivalent to $\nu$, then as shown in the first paragraph (and using the notation established there) there is some countable subset $\boldsymbol{C}$ of $\boldsymbol{L}$ such that $\mu_{C}$ and $\nu_{c}$ are not equivalent. But the operator $T_{C}$ induced by sending $x^{\mu}$ to $x^{\nu}$ for $x \in \boldsymbol{L}_{C}$ is precisely the restriction of $T$ to those elements in $\boldsymbol{L}_{\mu}$ which come from $\boldsymbol{L}_{\boldsymbol{c}}$. Now, the restriction of $T$ to a subspace is again an equivalence operator, so $T_{c}$ extends to an equivalence operator from $\overline{(\boldsymbol{L} \boldsymbol{c})})_{\mu}$ to $\overline{\left(\boldsymbol{L}_{\boldsymbol{C}}\right)_{\nu}}$, which contradicts the separable case of the theorem.

Also, in reviewing [1], E. Nelson noticed that Lemma 1 is misstated. It should read "positive" instead of "self-adjoint," and, in (b), " $A^{2}-I$ " rather than " $(A-I)^{2}$."

\section{BIBLIOGRAPHY}

1. J. Feldman, Equivalence and perpendicularity of Gaussian processes, Pacific J. Math., Vol. 8 No. 4, 1958.

2. J. von Neumann, Charakterisierung des spektrums eines integral-operatoren, Actualites Sci. Ind. 229, Paris, 1935. 


\section{PACIFIC JOURNAL OF MATHEMATICS}

EDITORS

David Gilbarg

Stanford University

Stanford, California

R. A. Beaumont

University of Washington

Seattle 5 , Washington
A. L. Whiteman

University of Southern California

Los Angeles 7, California

L. J. PAIGE

University of California

Los Angeles 24, California

\section{ASSOCIATE EDITORS}

\author{
E. F. BECKENBACH \\ C. E. BURGESS \\ E. HEWITT \\ A. HORN
}

\author{
V. GANAPATHY IYER \\ R. D. JAMES \\ M. S. KNEBELMAN \\ L. NACHBIN
}
I. NIVEN
E. G. STRAUS
T. G. OSTROM
G. SZEKERES
H. L. ROYDEN
F. WOLF
M. M. SCHIFFER
K. YOSIDA

\section{SUPPORTING INSTITUTIONS}

\author{
UNIVERSITY OF BRITISH COLUMBIA \\ CALIFORNIA INSTITUTE OF TECHNOLOGY \\ UNIVERSITY OF CALIFORNIA \\ MONTANA STATE UNIVERSITY \\ UNIVERSITY OF NEVADA \\ OREGON STATE COLLEGE \\ UNIVERSITY OF OREGON \\ OSAKA UNIVERSITY \\ UNIVERSITY OF SOUTHERN CALIFORNIA
}

\author{
STANFORD UNIVERSITY \\ UNIVERSITY OF TOKYO \\ UNIVERSITY OF UTAH \\ WASHINGTON STATE COLLEGE \\ UNIVERSITY OF WASHINGTON \\ $* \quad * \quad *$ \\ AMERICAN MATHEMATICAL SOCIETY \\ CALIFORNIA RESEARCH CORPORATION \\ HUGHES AIRCRAFT COMPANY \\ SPACE TECHNOLOGY LABORATORIES
}

Mathematical papers intended for publication in the Pacific Journal of Mathematics should be typewritten (double spaced), and the author should keep a complete copy. Manuscripts may be sent to any one of the four editors. All other communications to the editors should be addressed to the managing editor, L. J. Paige at the University of California, Los Angeles 24, California.

50 reprints per author of each article are furnished free of charge; additional copies may be obtained at cost in multiples of 50 .

The Pacific Journal of Mathematics is published quarterly, in March, June, September, and December. The price per volume (4 numbers) is $\$ 12.00$; single issues, $\$ 3.50$. Back numbers are available. Special price to individual faculty members of supporting institutions and to individual members of the American Mathematical Society: $\$ 4.00$ per volume; single issues, $\$ 1.25$.

Subscriptions, orders for back numbers, and changes of address should be sent to Pacific Journal of Mathematics, 2120 Oxford Street, Berkeley 4, California.

Printed at Kokusai Bunken Insatsusha (International Academic Printing Co., Ltd.), No. 6, 2-chome, Fujimi-cho, Chiyoda-ku, Tokyo, Japan.

PUBLISHED BY PACIFIC JOURNAL OF MATHEMATICS, A NON-PROFIT CORPORATION

The Supporting Institutions listed above contribute to the cost of publication of this Journal, but they are not owners or publishers and have no responsibility for its content or policies. 


\section{Pacific Journal of Mathematics}

\section{Vol. 9, No. 4 \\ August, 1959}

Frank Herbert Brownell, III, A note on Kato's uniqueness criterion for

Schrödinger operator self-adjoint extensions ............... 953

Edmond Darrell Cashwell and C. J. Everett, The ring of number-theoretic

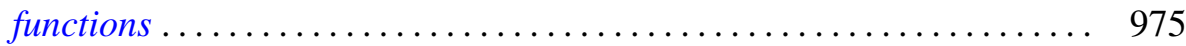

Heinz Otto Cordes, On continuation of boundary values for partial

differential operators ............................. 987

Philip C. Curtis, Jr., n-parameter families and best approximation . . . . . . 1013

Uri Fixman, Problems in spectral operators . . . . . . . . . . . . . . . 1029

I. S. Gál, Uniformizable spaces with a unique structure .............. 1053

John Mitchell Gary, Higher dimensional cyclic elements ............ 1061

Richard P. Gosselin, On Diophantine approximation and trigonometric

polynomials ..................................... 1071

Gilbert Helmberg, Generating sets of elements in compact groups ........ 1083

Daniel R. Hughes and John Griggs Thompson, The H-problem and the

structure of $H$-groups .................................. 1097

James Patrick Jans, Projective injective modules ................. 1103

Samuel Karlin and James L. McGregor, Coincidence properties of birth and

death processes ..................................... 1109

Samuel Karlin and James L. McGregor, Coincidence probabilities ........ 1141

J. L. Kelley, Measures on Boolean algebras ................... 1165

John G. Kemeny, Generalized random variables ................... 1179

Donald G. Malm, Concerning the cohomology ring of a sphere bundle ... . . 1191

Marvin David Marcus and Benjamin Nelson Moyls, Transformations on

tensor product spaces .................................. 1215

Charles Alan McCarthy, The nilpotent part of a spectral operator ........ 1223

Kotaro Oikawa, On a criterion for the weakness of an ideal boundary

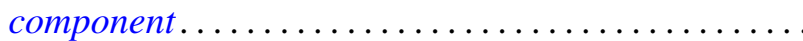

Barrett O'Neill, An algebraic criterion for immersion . . ............... 1239

Murray Harold Protter, Vibration of a nonhomogeneous membrane ... . . . . 1249

Victor Lenard Shapiro, Intrinsic operators in three-space . . . . . . . . . . . 1257

Morgan Ward, Tests for primality based on Sylvester's cyclotomic

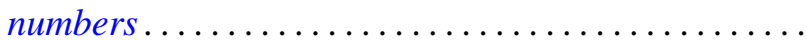

L. E. Ward, A fixed point theorem for chained spaces ....

Alfred B. Willcox, Šilov type $C$ algebras over a connected locally compact

abelian group..................................... 1279

Jacob Feldman, Correction to "Equivalence and perpendicularity of

Gaussian processes" ........................ 